\title{
Electronic Information Engineering "3+4" Research on the Cultivation of the Talents Training of the Educational System of the Secondary and Higher Vocational Colleges
}

\author{
Liu Qiang* \\ JiLin Engineering Normal University \\ Changchun, Jilin, China \\ e-mail: arnold0110@sina.com \\ * Corresponding Author
}

\author{
Zhang Na \\ College of Art and Design \\ Shenyang Jianzhu University \\ Shenyang, China
}

\begin{abstract}
The level of Vocational Education in China can be divided into vocational secondary schools, technical schools, secondary vocational schools and higher vocational schools, and only higher vocational education in higher education. Because people pay attention to vocational education is not enough, the training system of vocational education is not perfect, the talent training program is not perfect. In particular, vocational and technical colleges and secondary vocational schools in the training program needs to be docked, the need for personnel training system. Only in this way can we develop the social needs of high-level blue collar technicians. We have a lot of talent training mode of science education in our country, but the research on the training mode of the vocational and technical college and the secondary vocational school is very little. Now our school is applied transformation and development, as a pilot project of electronic information engineering carried out " $3+4$ " talent training mode, the vocational study for three years, and ascend to the undergraduate learning four years. That requires we study and formulate the " $3+4$ secondary and higher vocational college educational system through personnel training program. In this aspect, we have carried on the practice, has accumulated some experience, we have carried on the summary in the original running school experience.
\end{abstract}

Keywords- vocational education; Electronic Information Engineering; Talent training program

\section{INTRODUCTION}

From the type of higher education, we can divide the higher education into two categories, namely, science education and vocational education. Science Education in our country can be considered as ordinary higher education, it is mainly research and development of applied talents, including two types: first, the theory of talent, is to study and discover the objective law and the results of the scientific principle as its own responsibility; two is the engineering personnel, the scientific principles into planning decision-making and new technology research and development. It is the cultivation of talents with knowledge as the value orientation of the knowledge, to impart knowledge to the center, the basic theory of the requirements of the system, complete discipline theory. Vocational education is the technology of applied talents, also divided into two categories: first, research and development personnel, different from the engineering of science education personnel, this type of talent need to have a certain professional background requirements; two is the position of talent, they are the production, construction, management, services, the first line staff. This type of education is the ability based on the value orientation of the ability of people, with the ability to develop as the center, in order to apply design principles, basic theory to achieve general, enough for the degree, professional knowledge and practical requirements, teaching should be combined with the actual work.

However, with the continuous development of society and economy, the employment of modern society and the rapid changes in employment, to further promote the higher education and production departments, and strengthen the importance of Vocational education. Since the end of twentieth Century, the number of colleges and universities in China has been increasing since the enrollment expansion of colleges and universities. Generally speaking, senior management personnel, senior research professionals, application of professional and technical personnel, high-quality technical workers is a positive Pyramid, and China's employment team was inverted Pyramid type, practical personnel and skilled workers a serious lack of balance by the talent structure, we can see the current social and economic development of Vocational and technical personnel needs and the urgent need to develop vocational education. To this end, the state has formulated a number of policies and measures to promote the great development of vocational education to meet the needs of technical personnel. If the Ministry of education put forward the development strategy for the application of the transformation of institutions of higher learning.

Compared to China's vocational education is not attached to the developed countries in Europe and the United States in this regard is relatively perfect. Universities in the United States can be divided into three categories, of which the third category is to focus on Vocational and technical community college, junior college, college and vocational schools, they are generally closely combined with the needs of the professional market to train professional and technical personnel and professional skilled workers. As of the end of 2006, a total of 1202 community colleges in the United States, 
enrollment reached 11 million 600 thousand people, community college students accounted for $45 \%$ of the total number of American University, nearly $60 \%$ of the college age population to apply for a two-year community college or technical college, you can see the United States higher education in science education and vocational education is relatively balanced, vocational education personnel training system is relatively sound.

Higher vocational education in German higher education can be described as a sudden appearance of a new force, formed an absolute advantage, school number has reached more than 130 , accounted for about half of the total number of colleges and universities is more, and a development trend; from the perspective of the distribution of school enrolment, approximately one-half of the freshmen entering the University, a third new entered colleges and vocational colleges, one sixth of the freshmen into comprehensive university, art, teachers college. From the survey results, $60 \%$ of students expect to attend higher vocational schools and professional, the unemployment rate is lower than the University, so that citizens to point to the University, the original support of the interest groups in Colleges and universities have turned to the attention of the higher vocational schools, the German vocational education personnel training system is very sound, thus accelerating the construction and development of Higher Vocational Education in germany.

The level of Vocational Education in China can be divided into vocational secondary schools, technical schools, secondary vocational schools and higher vocational schools, and only higher vocational education in higher education. Because people pay attention to vocational education is not enough, the training system of vocational education is not perfect, the talent training program is not perfect. In particular, vocational and technical colleges and secondary vocational schools in the training program needs to be docked, the need for personnel training system. Only in this way can we develop the social needs of high-level blue collar technicians. We have a lot of talent training mode of science education in our country, but the research on the training mode of the vocational and technical college and the secondary vocational school is very little.Now our school is applied transformation and development, as a pilot project of electronic information engineering carried out " $3+4$ " talent training mode, the vocational study for three years, and ascend to the undergraduate learning four years. That requires we study and formulate the " $3+4$ secondary and higher vocational college educational system through personnel training program. Our experience in this area is relatively small, we need to summarize and develop the experience of running school

\section{MAIN RESEARCH CONTENTS}

Explore the new talent cultivation mode, the formation of electronic information engineering specialty " $3+4$ " secondary and higher vocational education system through the talent training scheme, namely, the achievement of vocational schools and vocational and technical colleges and students win the school depth of cooperative education mode. Through such a talent training model of students, to achieve the ability oriented value orientation of the people, the ability to develop as the center, in order to apply design principles, basic theory to achieve general, enough for the degree, professional knowledge and practical requirements.

Such Vocational Education: first, in line with the development of vocational education law; two is to meet the vocational college students system learning education laws; three is in line with the requirements of the development of Vocational Education in our province; four is the electronic information engineering students through such system training model, is the application of talent, only different from other colleges and universities of electronic information engineering professional students.Our country related content through in-depth study about the transformation of colleges and universities to application and spirit, grasp the connotation of "on the occupation education development planning outline" long term education reform and development in Jilin Province, the Provincial Department of education for the support of relevant departments, the current situation of talent on the mode of secondary vocational school culture industry in Jilin province to conduct research; Research Report of talent training plan of medium occupation school; talent training program of higher education research and the formation of the Research Report; "3+4" electronic information engineering of secondary and higher occupation colleges through academic personnel training scheme and Feasibility Research Report; employ wellknown experts, the development of vocational education personnel training mode of vocational education and related laws the frontier theory and method; the formation of School of electronic information engineering " $3+4 "$ secondary and higher occupation colleges through talents Training innovative plan; building up the feedback and evaluation system;Our main research content is

A. research on the talent training program of secondary vocational schools and the talent training program of Vocational and technical colleges. To understand the specific requirements and development trends of electronic information engineering in secondary vocational schools, to study the teaching plan, training room construction and quality improvement of Electronic Information Engineering Specialty in Vocational and technical colleges, and to modify the teaching plan of electronic information engineering major in Vocational Colleges and vocational colleges.

B. To find the vocational and technical college and Vocational College of electronic information engineering professional " $3+4$ " through the mode of operation of the specific mode of operation, to achieve a win-win situation. A study on the connection between Higher Vocational and Technical Teachers College Students in Vocational Colleges and learning content while learning to teach, practice teaching content.

C. The problem of teaching, teaching in the study of Secondary Vocational School of electronic and information engineering project management and evaluation of students. Of secondary vocational school 
students in post teaching practice in the process to carry out supervision and management, the need and 4 secondary vocational schools to establish cooperation mechanism, the construction of " $3+4$ " training of students of the joint monitoring system and comprehensive evaluation system.

D . Study of the secondary vocational school of electronic information engineering students in the composition of the situation, learning, learning characteristics, especially in the secondary vocational school of electronic information engineering professional training programs in the curriculum, to provide reference for the province to recruit students. The formation of secondary vocational school, college, undergraduate education programs, improve the quality of teaching in Vocational colleges.

The key problem we have to solve in the research content is:

A.The talent training program of the secondary vocational school of electronic information engineering and the connection of the talent training program in Vocational and technical colleges.

B.Sharing of learning resources; sharing and co construction of practice training base.

C.The evaluation system of the electronic information engineering professional skill type talent.

\section{RESEARCH METHOD}

The research methods used in this paper include: historical research methods; comparative study; literature research; research methods; discussion and conference.

A. The historical research method -- on Germany, the United States, Britain, Japan and other countries of the vocational education advanced talent training program mainly uses the historical research method, focusing on the track of the development of vocational education personnel training, analysis of the problems faced by the development of vocational education personnel, to take countermeasures, summed up the relevant experience and rules.

B. The comparative study of the law -- mainly including country, international research and the comparative study in a narrow sense.

Country study is mainly used to sort out the problems and Countermeasures of Vocational Education in various countries; international research on the key issues of the development of vocational education personnel training; the comparative study mainly used in China's vocational education personnel training and other education personnel training.

C. Literature research method is mainly used for the professional education personnel training theoretical connotation of finishing, data collection and collation.

D. Research method, this paper as much as possible obtain first-hand information through the investigation and study method, is mainly used to explore the new talent cultivation mode, electronic information engineering professional " $3+4$ secondary and higher vocational college educational system through personnel training, vocational colleges and higher vocational and technical colleges and universities and students win the school depth of cooperative education mode.

E.Discussion, conference.

Project leader for many years engaged in electronic information engineering education, in many years of teaching and research work has accumulated more experience in the development of electronic information engineering professionals and vocational education research experience. Project members are engaged in electronic information engineering professional teachers, has a wealth of teaching experience. Project team members are presided over and participate in higher education and vocational education at the provincial level, Colonel issue, such as education scientific planning, subject to the adjustment of economic structure in Jilin Province of undergraduate talents demand analysis and countermeasure research on the training of "," based on vocational education cooperation between colleges and universities talent training mode, innovation ", provincial education department issues the Jilin Province employment status of graduates in local undergraduate colleges and universities and Countermeasures" and other, in the study of these topics accumulated a lot of research experience.

\section{CONCLUSION}

Task group, a total of 7 members, including professional and technical title structure is a professor of 1 people, 1 associate professors, lecturers and researchers a total of 5 people; the academic structure of 1 doctoral students, 2 doctoral students, 4 master's degree students. 6 teachers who are engaged in professional teaching work, and 1 of them are engaged in education management. Task group members are mostly engaged in Vocational Education Teaching for many years, the study of teachers, research materials and accumulation of research experience are the advantages of this project, and the project team members to ensure adequate time and energy into the research work of the project. The school has the national vocational education literature data inventory, with complete vocational education information and more than 100 middle and higher vocational school employment and practice base. The library has occupation education books more than 30 books, and has close relationship with the National hundreds of Vocational colleges. The school provides a laboratory, providing 10 computers, providing access to information on the internet.

Through the research of this topic we got the following results: Construction of vocational education and vocational education in vocational schools in the preliminary model of the industrial group, completed the electronic information engineering professional "3+4" secondary and higher vocational institutions to develop talent training programs, vocational and technical colleges and vocational schools in cooperation with the construction of practical training base;Formation of the electronic information engineering " $3+4 "$ secondary and higher vocational school system through the specific implementation of personnel training programs, and to practice; published electronic information engineering 
professional "3+4" secondary and higher vocational institutions through personnel training mode innovation research related papers 1; form a virtuous circle of Vocational Education in our province.

\section{REFERENCES}

[1] The national vocational education reform and innovation action plan.

[2] Jiang Dayuan. The new reform and development of the German occupation education $[\mathrm{J}]$. dynamic Chinese Occupation Technology Education 2010 (5)

[3] Wang Wenjin. A review of the international literature on the attraction of vocational education [J]. 2010 (4) of China's Vocational and technical education.

[4] "The outline of the long term education reform and development plan of Jilin province".
[5] Zhao Zhiqun. From the experience and lessons of foreign countries to see the establishment of modern vocational education system should pay attention to several issues $[\mathrm{J}]$. vocational and technical education 1995 (4).

[6] Chen Bin. The relationship between vocational education and the construction of a harmonious society from the perspective of educational economics [J]. Liaoning education research 2005 (11).

[7] Sun Lin, social transformation and vocational education policy adjustment [J]. Vocational Education Forum 2006 (5)

[8] Jiang Dayuan. The latest reform and development of Vocational Education in Germany (2010) (5)

[9] Wang Wenjin. A review of the international literature on the attraction of vocational education [J]. 2010 (4) of China's Vocational and technical education

[10] Danah boyd. Social Media Changing our Information Ecology[J]. ITI Bloggers,2008 (22):112-13 